\title{
EFFECT OF TENDING AND THINNING ON SPATIAL AND CARBON DISTRIBUTION PATTERNS OF NATURAL MIXED BROADLESF-CONIFER SECONDARY FOREST IN XIAOXING'AN MOUNTAINS, PR CHINA
}

\author{
WANG, Z. C. - LI, Y. X. ${ }^{*}-$ MENG, Y. B. - WANG, C. \\ College of Engineering and Technology, Northeast Forestry University, Harbin 150040, PR \\ China \\ *Corresponding author \\ e-mail: yaoxiangli@nefu.edu.cn; phone: +86-136-4450-5681 \\ (Received $17^{\text {th }}$ Jan 2021; accepted $1^{\text {st }}$ Oct 2021)
}

\begin{abstract}
Four 0.25-ha natural mixed broadleaf-conifer secondary forest plots (CK, $\left.\mathrm{T}_{15}, \mathrm{~T}_{25}, \mathrm{~T}_{35}\right)$ were established in Xiaoxing'an Mountains, PR China. The spatial pattern of plant community was studied by using O-ring statistical analysis method and field survey was carried out to estimate the carbon storage of trees. The research was done in order to explore the effects of different thinning intensities on the spatial and carbon distribution patterns of natural secondary forests in order to provide a reasonable forest management method. We described three main findings. (1) The spatial patterns of either the whole forest or the dominant tree species almost took on a random distribution. Thinning changed the distribution patterns of forest at $\leq 4 \mathrm{~m}$ scales, and the distribution changed from random distribution to cluster distribution. (2) It also altered the distribution of dominant tree species, the spatial correlation between dominant species changed from partial negative associations to independence or partial positive associations, and the negative associations in $T_{35}$ plot were the lowest. (3) The carbon storage in the $T_{15}$ plot was significantly lower than that in the other plots at $\geq 10 \mathrm{~m}$ scales. The carbon storage in the $\mathrm{T}_{35}$ plot was higher than that in the CK plot at almost all scales. In conclusion, the $\mathrm{T}_{35}$ plot optimized the forest structure and it was more beneficial to the carbon storage of natural mixed broadleaf-conifer secondary forests in Xiaoxing'an Mountains after 8 years thinning.
\end{abstract}

Keywords: thinning intensity, O-ring statistical analysis, spatial pattern, spatial correlation, carbon storage

\section{Introduction}

Natural disturbance and anthropogenic disturbance work in parallel with competition to shape the spatial pattern of vegetation in boreal ecosystems (Felinks and Wiegand, 2008; Gray and He, 2009). In natural ecosystems, altitude factors, climate factors, precipitation factors and soil factors worked together on the spatial distribution pattern of trees (Moeur, 1993). Among human factors, tending thinning was an important part of forest managements which changed the forest spatial structure and spatial distribution pattern, so the spatial correlation among different species and biomass distributions are also affected (Li et al., 2011; Duan et al., 2019). At present, most of the existing studies were about the effect of selective cutting on natural forest or tending thinning on plantation forest in population structures and distribution patterns (Shen et al.,2013; Wu et al., 2015). However, few scholars have studied the impact of tending thinning on nature secondary forest distribution patterns.

A powerful tool to characterize the spatial pattern and spatial correlation is point patterns analysis, individual is regarded as a point with coordinate figure in a twodimensional space plane. The dominant tree species constitute a point set, and then, it will be drawn as a point graph. The spatial pattern and inter-specific association at 
different scales are described on the basis of point graph (Diggle, 2003; Illian et al., 2008; Law et al., 2009). This method is more rigorous in data requirements and it can maximize the use of spatial information. On the one hand, the point pattern analysis can judge the distribution state of population. On the other hand, it can describe diverse intra- and interspecies relationships at different scales (Yao, et al., 2020). As most intertree interactions are expected to occur within $10 \mathrm{~m}$ scales (Stoyan and Penttinen, 2000; Getzin et al., 2008), so plots $<1$ ha have been widely used to investigate tree spatial patterns in different environments (Svoboda et al., 2010; Aakala et al., 2012; Petritan et al.,2014; Sanatan and Bradley, 2018). However, some researchers have analyzed the spatial pattern of dominant tree species at different scales in plots $<1$ ha but drew different conclusions. For example, Yang and Li (1985) reported that Tilia amurensis were randomly distributed in several $10 \mathrm{~m} \times 10 \mathrm{~m}$ plots, while the results of Du (2012) suggested that Tilia amurensis showed a significant cluster distribution in a small scale of 0.16 ha permanent plot. These studies drew different conclusions because they had different scales, different analysis methods, and different natural and human factors.

A large number of primary forests have been converted into secondary forests due to the degradation of top plant communities. More than 50\% of China's forest areas are secondary forests (Du et al., 2013), and natural mixed broadleaf-conifer secondary forests are typical forest types in Northeast China. Xiaoxing'an Mountains are the main natural forest areas in Northeast China. It is significant to explore the effects of different tending and thinning intensities on the spatial and carbon distribution patterns of natural mixed broadleaf-conifer secondary forests. It is very important for reasonable management forests and the development of forestry carbon sinks. In this study, the sites after 8 years tending thinning (thinning intensities were about $0,15 \%, 25 \%$ and $35 \%$ ) in Xiaoxing'an Mountains were selected, and analyzed the spatial distribution pattern and carbon distribution pattern of these plots through sample plot investigation. Using the spatial point pattern analysis method, the spatial distribution patterns and associations of dominant tree species of different tending and thinning intensities were analyzed. It provides the basis for further scientific management of natural secondary forests of Xiaoxing'an Mountains. The O-ring statistic was used for point pattern analysis at various scales (Hao et al., 2007). In this study, it was used to analyze the spatial patterns and the spatial correlations between different dominant tree species.

In order to evaluate the tending and thinning effects of natural secondary forest in Xiaoxing'an Mountains comprehensively, the spatial structure and carbon storage of stands at different scales were used as indicators to explore the optimal intensity after thinning for 8 years.

\section{Materials and methods}

\section{Study sites}

We conducted this study in natural mixed broadleaf-conifer secondary forest located in Dongfanghong Forest Farm, Yichun City, Heilongjiang province, Northeast China, with latitude $128^{\circ} 37^{\prime} 46^{\prime \prime}-129^{\circ} 17^{\prime} 50^{\prime \prime}$ and longitude $46^{\circ} 50^{\prime} 8^{\prime \prime}-47^{\circ} 21^{\prime} 32^{\prime \prime}$ (Fig. 1). The average elevation of this area is $600 \mathrm{~m}$ above sea level, the average slope is $14^{\circ}$ in the northwest direction. The average annual precipitation is $661 \mathrm{~mm}$, mainly concentrates in July and August. The top climatic community in the study area is mixed broadleafconifer secondary forest, and the dominant tree species are Picea asperata, Abies fabric, Acer mono, Acer tegmentosum, Fraxinus mandshurica Rupr, Pinus koraiensis Sieb. et 
Zucc and Tilia tuan Szyszyl. The types of shrubs include Acanthopanax senticosus (Rupr. Maxim.) Harms, Spodiopogon cotulifer (Thunb) and so on.
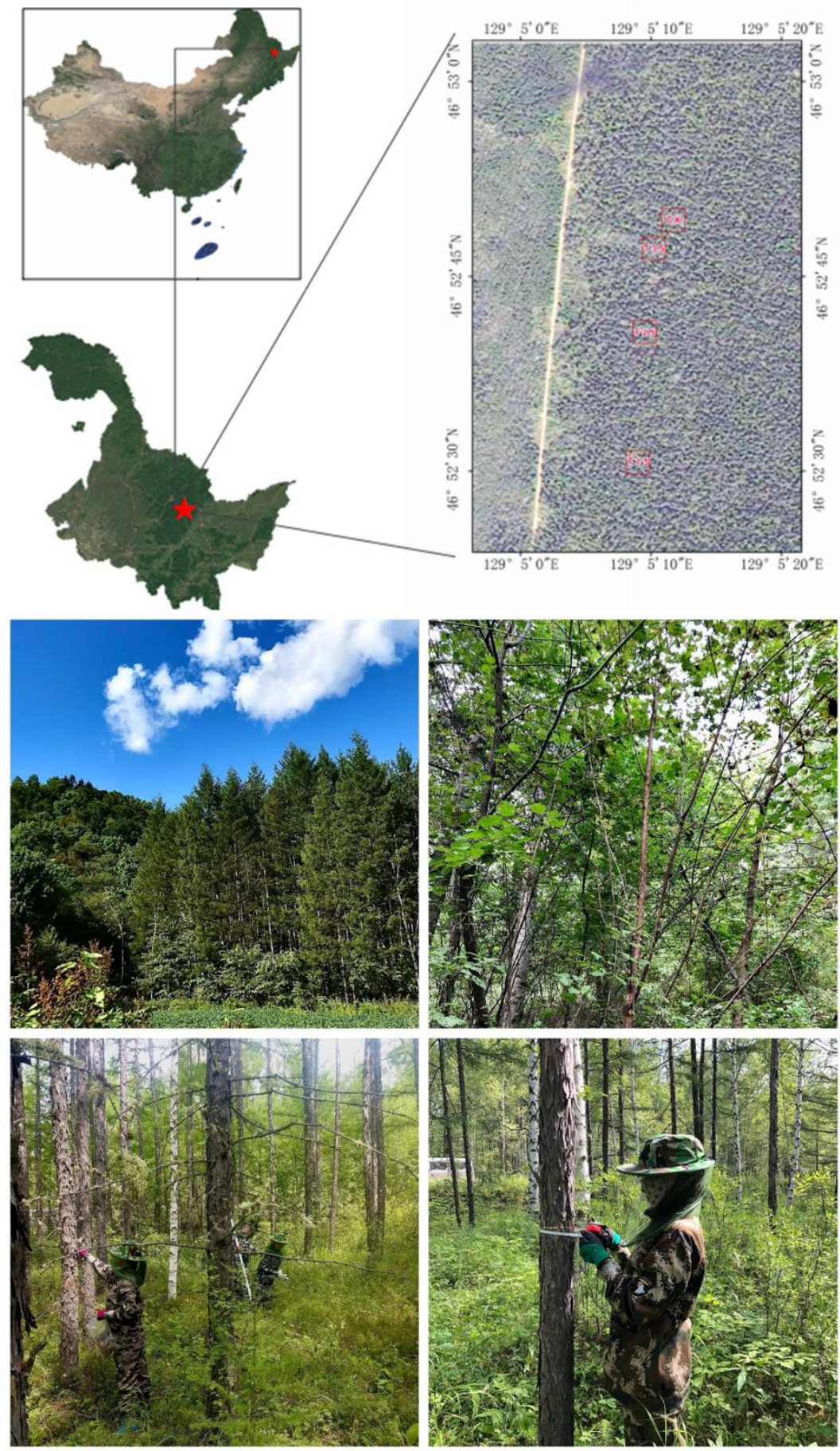

Figure 1. The Research area of Xiaoxing'an Mountains

\section{Data collection}

In 2012, the experimental sites with relatively consistent stand conditions were selected for tending thinning. At the same time, repair planting was carried out in the 
thinning sites, the replanting trees included Pinus koraiensis Sieb. et Zucc., Picea asperata, and Larix gmelinii. These experimental sites were surveyed repeatedly in August 2019. In these sites, we established four 0.25 -ha $(50 \mathrm{~m} \times 50 \mathrm{~m})$ plots, which marked as CK (control area, non-thinning), $\mathrm{T}_{15}$ (thinning intensity was about $15 \%$ ), $\mathrm{T}_{25}$ (thinning intensity was about 25\%), $\mathrm{T}_{35}$ (thinning intensity was about $35 \%$ ). Each plot was divided into one hundred $5 \mathrm{~m} \times 5 \mathrm{~m}$ quadrates. Our survey was based on these $5 \mathrm{~m}$ $\times 5 \mathrm{~m}$ quadrates. All free-standing tree stems $\geq 5 \mathrm{~cm}$ diameter at breast height (DBH, $1.3 \mathrm{~m}$ above the ground) have been measured. The measuring contents include tree species, coordinate position, $\mathrm{DBH}$, height, tree crown, branch height and so on. Table 1 shows the basic status of thinned forests.

Table 1. Basic status of thinning stand (mean $\pm S D$ )

\begin{tabular}{c|c|c|c|c|c|c}
\hline $\begin{array}{c}\text { Thinning } \\
\text { treatment }\end{array}$ & $\begin{array}{c}\text { Elevation } \\
(\mathbf{m})\end{array}$ & $\begin{array}{c}\text { Diameter at } \\
\text { breast height } \mathbf{( c m})\end{array}$ & $\begin{array}{c}\text { Tree } \\
\text { height } \mathbf{( m )}\end{array}$ & $\begin{array}{c}\text { Basal area at breast } \\
\left.\text { height } \mathbf{( m}^{\mathbf{2}} \cdot \mathbf{h m}^{-\mathbf{2}}\right)\end{array}$ & $\begin{array}{c}\text { Stand density } \\
\left(\mathbf{p l a n t} \cdot \mathbf{h m}^{-2}\right)\end{array}$ & $\begin{array}{c}\text { Canopy } \\
\text { density } \mathbf{( \% )}\end{array}$ \\
\hline $\mathrm{CK}$ & $457 \sim 492$ & $16.62 \pm 4.62$ & $11.69 \pm 3.06$ & $2.59 \pm 0.67$ & 958 & 90 \\
$\mathrm{~T}_{15}$ & $504 \sim 509$ & $13.53 \pm 2.97$ & $9.69 \pm 2.03$ & $2.38 \pm 0.53$ & 1183 & 92 \\
$\mathrm{~T}_{25}$ & $487 \sim 540$ & $15.96 \pm 3.45$ & $11.48 \pm 2.77$ & $1.96 \pm 0.46$ & 925 & 81 \\
$\mathrm{~T}_{35}$ & $468 \sim 499$ & $16.31 \pm 3.98$ & $11.09 \pm 2.43$ & $2.12 \pm 0.63$ & 733 & 76 \\
\hline
\end{tabular}

\section{Data analysis}

Ripley's K or L function have been used frequently in point pattern analysis (Rozas, 2006; Fajardo et al., 2006). Ripley's K or L function is used to analyze the spatial patterns of species in a circle of radius $r$ centered at one point. When the space scale increases, the Ripley's K or L function have the problem of small-scale accumulation, because the results include all information in the circle. Therefore, $\mathrm{O}-$ ring statistical analysis is developed on the basis of Ripley's $\mathrm{K}$ or L function and Mark function (Stoyan and Stoyan, 1994). The O-ring statistical analysis replaces the circles with rings, so cumulative effects on small scales are eliminated. The Oring statistical analysis gives an intuitive interpretation of a neighborhood density and is especially sensitive to small-scale effects (Wiegand and Moloney, 2004; Illian et al., 2008).

The O-ring statistics includes both univariate and bivariate statistics (Getzin et al.,2006). The univariate statistics are used to analyze the spatial pattern of one object, while the bivariate statistics are used to analyze the spatial association of two objects (pattern 1 and pattern 2). The choice of null models is very important to ensure the accuracy of data analysis in O-ring statistical analysis (Zhao et al., 2011). In this study, univariate O-ring statistics was used to analyze the distribution pattern of each dominant tree species in the sample plot. Bivariate O-ring statistics were used to analyze the spatial correlation between dominant tree species in the sample plot. For the univariate $\mathrm{O}$-ring statistic, analyze the spatial distribution of dominant tree species in each thinning plot, if there are no strong aggregation phenomena, complete spatial randomness (CSR) is chosen as the null model. If there are obvious indication of strong aggregation, the heterogeneous Poisson process was adopted. The confidence intervals of dominant tree species of spatial distributions were simulated by Monte Carlo. Departure from a given null model was tested by comparing the pair correlation 
function of point data with the 5th lowest and 5th highest value of 99 Monte Carlo simulation to generate an approximately $99 \%$ simulation envelope. If the point was above the upper envelope, it indicated clumped. If the points between the envelopes, it indicated random. If the points under the lower envelopes, it indicated regular. For the bivariate O-ring statistic, the spatial correlation between two dominant species in the experimental plots was compared using the CSR. According to Monte Carlo simulation results, in these analyses, points above the upper envelope indicated positive associations, points between the envelopes indicate spatial independence, and points below the lower envelope indicate negative associations. All point pattern analyses were conducted using Programita software (Wiegand and Moloney, 2004) and Spatstat library (Baddeley and Turner, 2005) in R (3.6.3). Details on the estimators of the summary statistics and edge correction used in Programita can be found in Wiegand and Moloney (2014).

\section{Cumulative carbon reserve estimation}

The biomass estimation of $P$. asperata and A. fabric were based on the biomass equations, which were established by $\mathrm{Hu}$ in this area (Hu et al., 2015). The biomass estimations of $A$. mono and $A$. tegmentosum were carried out by using the ten biomass models in Northeast China which established by Wang (2005). In each plot, 2 3 standard trees of dominant tree species were selected in order to avoid different carbon content which caused by different thinning intensities, different tree species and so on. Samples were taken from trunk, branches, leaves and skins of dominant tree species. And then the carbon content were determined by potassium dichromate oxidationexternal heating method in the laboratory.

The product of individual biomass and carbon content was the individual carbon storage, and cumulative carbon storages were obtained by accumulating the individual carbon storage of quadrats. To consider that the quadrats had various tree species, spatial distributions and growth states, so the cumulative carbon storages did not grow in a straight line on different spatial spaces. Therefore, ten quadrats of $5 \mathrm{~m} \times 5 \mathrm{~m}, 10 \mathrm{~m}$ $\times 10 \mathrm{~m}, 15 \mathrm{~m} \times 15 \mathrm{~m}, 20 \mathrm{~m} \times 20 \mathrm{~m}, 25 \mathrm{~m} \times 25 \mathrm{~m}, 30 \mathrm{~m} \times 30 \mathrm{~m}$ were generated randomly in the plots (Duan et al., 2015). It was used to analyze the partial characteristics of cumulative carbon reserves under different spatial patterns.

\section{Results}

\section{Stand structure}

There were 539 living trees of four dominant species with the $\mathrm{DBH} \geq 5 \mathrm{~cm}$ in four experimental plots (Fig. 2). The number of dominant tree species in the CK, T15, T25 and $\mathrm{T}_{35}$ plots were $141,158,114$ and 126 . In the $\mathrm{CK}$ plot, the DBH class distribution curves of $A$. fabric and A. mono were shifted to the right. It showed that $A$. fabric and $A$. mono had larger $\mathrm{DBH}$ in the $\mathrm{CK}$ plot. There were large numbers of A. tegmentosum whose DBH was from $6 \mathrm{~cm}$ to $10 \mathrm{~cm}$ in the $T_{15}$ plot. In the $T_{25}$ plot, the number of four dominant tree species was smaller than in the other plots, whose DBH was from $16 \mathrm{~cm}$ to $20 \mathrm{~cm}$. In the $\mathrm{T}_{35}$ plot, the number of $A$. fabric was the largest, and the number of $P$. asperata was significantly less than other dominant species. In four experimental plots, the length of $A$. fabric step curve was the largest, it suggested that the individual differentiation of $A$. fabric was obvious. 

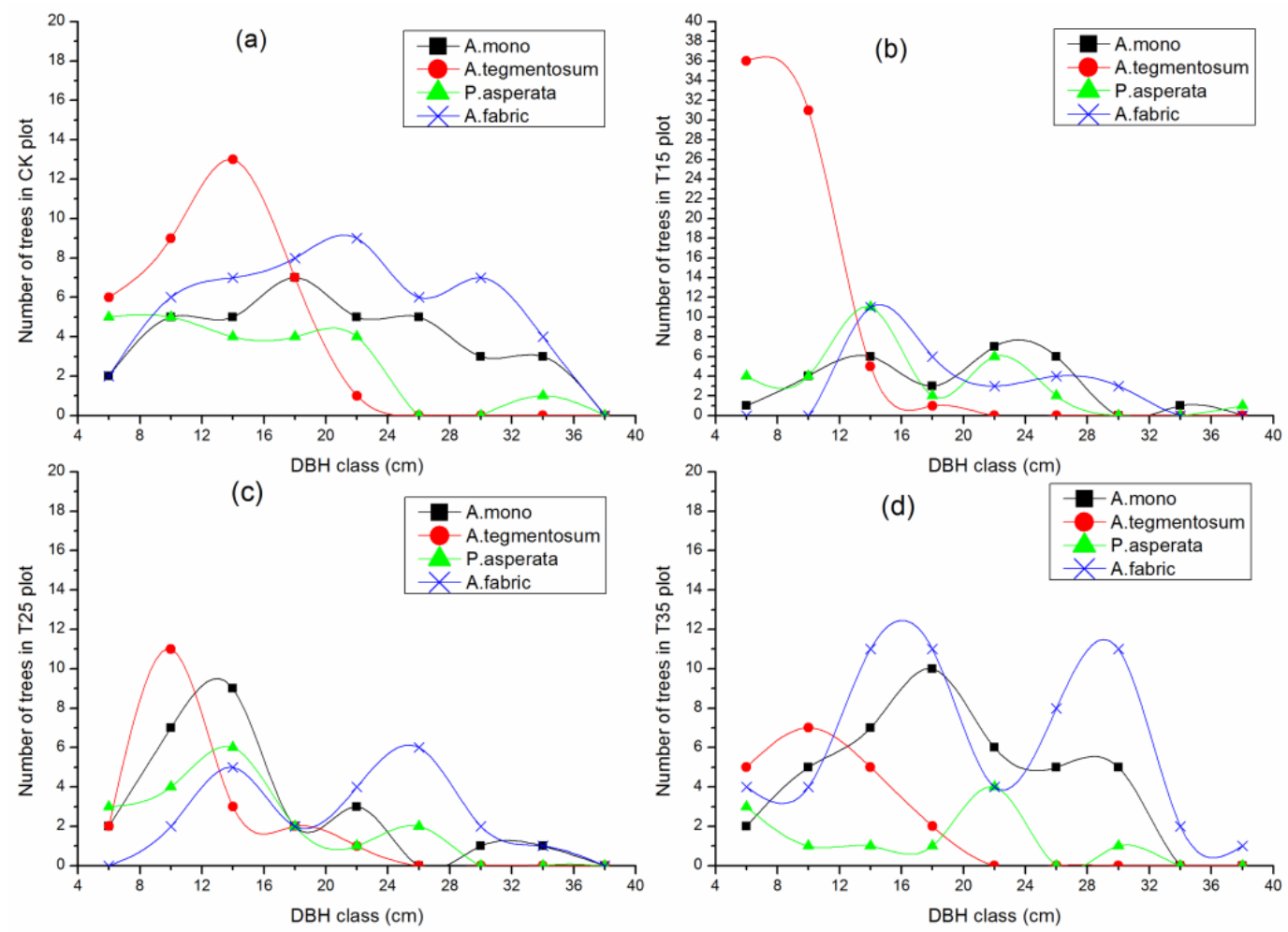

Figure 2. The DBH class distributions of four dominant tree species in the 0.25-ha forest plot. (a) CK plot (b) T15 plot (c) T25 plot (d) T35 plot

The structure of DBH size class of dominant trees in three thinning plots was significantly different from that in the CK plot. The test of normality for $\mathrm{DBH}$ of dominant tree species in four experimental plots showed that thinning caused the distribution curve changed from normal distribution to non-normal distribution. $(\mathrm{P}<0.05)$ (Table 2).

Table 2. Test for normality in different DBH of all dominant tree species

\begin{tabular}{c|c|c|c|c}
\hline Test & $\mathbf{C K}$ & $\mathbf{T}_{\mathbf{1 5}}$ & $\mathbf{T}_{\mathbf{2 5}}$ & $\mathbf{T}_{\mathbf{3 5}}$ \\
\hline Skewness & 0.223 & 0.918 & 0.530 & 0.272 \\
Kurtosis & -0.197 & 0.561 & -0.444 & -0.887 \\
Shapiro-Wilk to check $P$ & 0.148 & 0.002 & 0.004 & 0.007 \\
\hline
\end{tabular}

$\mathrm{P}>0.05$, the diameter order curve conforms to the normal distribution

\section{Spatial patterns of dominant tree species under different thinning intensity}

According to the distribution of dominant tree species in the CK plot and three thinning plots (Fig. 3), it could be seen that: Tending thinning did not change the distribution status of forests in all plots, but it changed the distribution ratio of dominant tree species. There were great differences in the densities of different tree species in some local areas, and the densities of the dominant tree species varied greatly with the changing spatial positions. It could be seen from (Figs. 2 and 3) that there were obviously more juvenile $A$. tegmentosum in the $\mathrm{T}_{15}$ plot than other plots, and in this plot, 
A. tegmentosum had many initiation distribution and rosette distribution, it was very consistent with the characteristics of secondary forests.
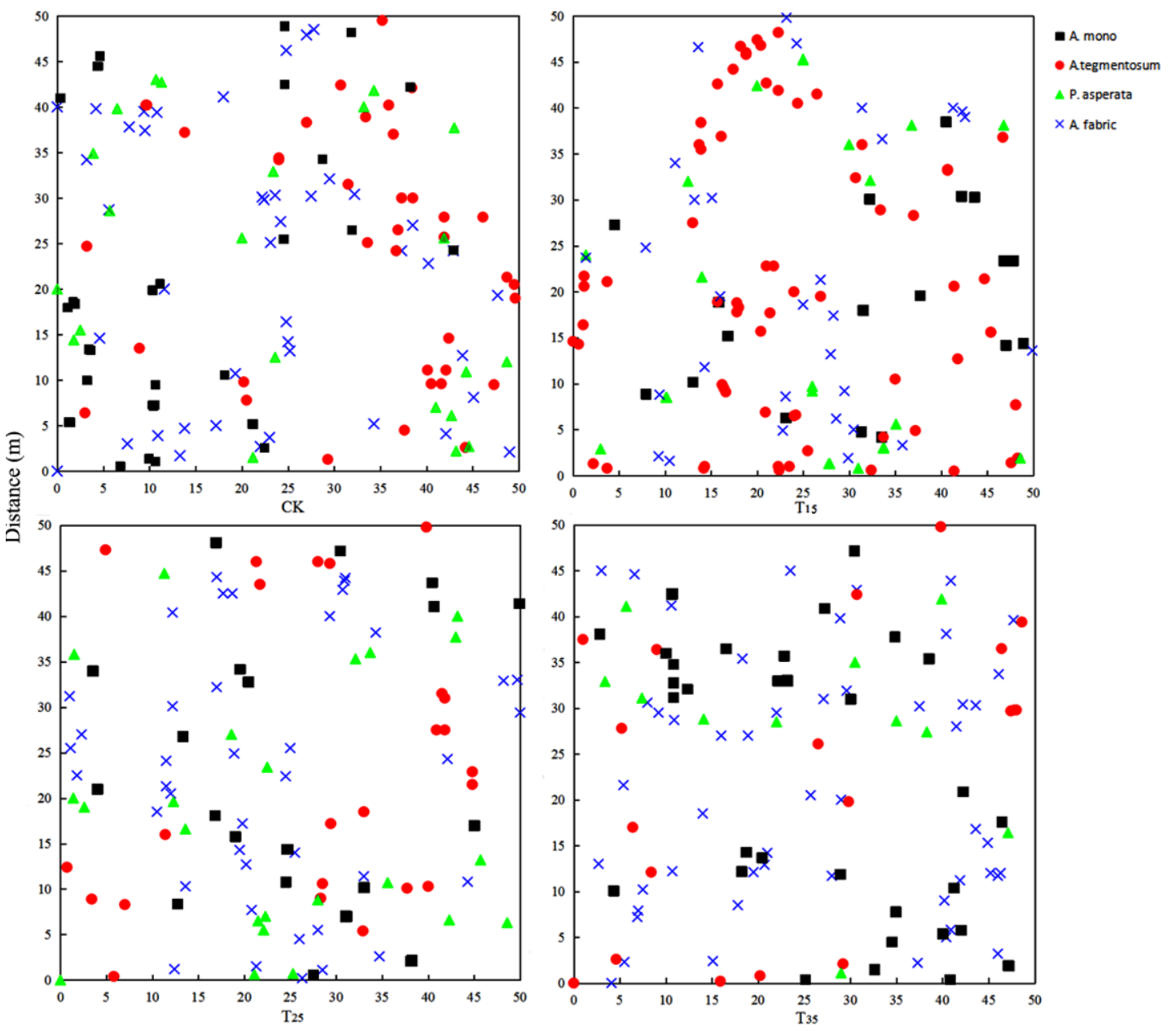

Figure 3. Spatial distribution of dominant tree species in various plots

When the four dominant tree species were analyzed together (Fig. 4), (a) was randomly distributed at scales $\leq 25 \mathrm{~m}$, while (b), (c) and (d) were clustered at smaller scales. (b) was also significantly aggregated at $20 \mathrm{~m}$ scale. (c) and (d) showed regular distributions at some scales, such as $12 \mathrm{~m}, 17 \mathrm{~m}$ and $21 \mathrm{~m}$ scales in (c) and $9 \mathrm{~m}$, 18 19 $\mathrm{m}$ scales in (d).

A. mono showed significant clustering when the spatial scales were $1 \mathrm{~m}$ and $8-9 \mathrm{~m}$, but showed regular at $16 \sim 17 \mathrm{~m}$ scales in the CK plot. Meanwhile, in the 3 thinning plots, as the intensity of thinning increases, the clustered distribution of $A$. mono were more, such as: the scale at $10 \mathrm{~m}$ in the $\mathrm{T}_{15}$ plot, $8-10 \mathrm{~m}$ in the $\mathrm{T}_{25}$ plot and $0-1 \mathrm{~m}, 7-$ $8 \mathrm{~m}, 17 \mathrm{~m}$ in the $\mathrm{T}_{35}$ plot. A. tegmentosum were randomly distributed at almost all scales, while, at the scale of $0 \sim 3 \mathrm{~m}$ in the $\mathrm{T}_{15}$ plot and $21 \mathrm{~m}$ in the $\mathrm{T}_{35}$ plot, the clusters were appeared. $P$. asperata were only clustered at small scales of the $\mathrm{CK}$ plot and the $\mathrm{T}_{15}$ plot, and randomly distributed at larger scales. At different scales, A. fabric showed random distribution basically, however, at some scales, they were clustered, such as $2 \mathrm{~m}$ in the CK plot, $9 \mathrm{~m}$ in the $\mathrm{T}_{15}$ plot, $3 \mathrm{~m}$ and $8-9 \mathrm{~m}$ in the $\mathrm{T}_{25}$ plot, respectively (Fig. 5). 

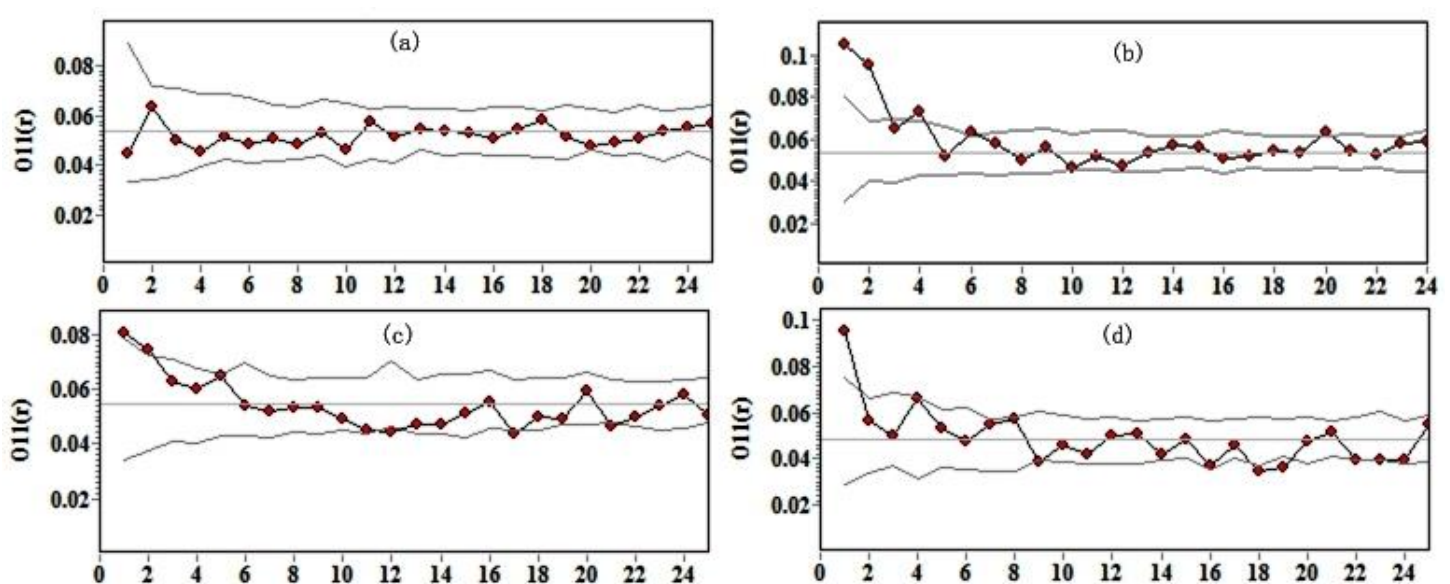

Figure 4. The spatial distribution pattern of four dominant tree species. (a) CK plot. (b) $T_{15}$ plot. (c) $T_{25}$ plot. (d) $T_{35}$ plot. Solid lines indicate ring statistics $O 11(r)$. Dotted lines indicate the

upper and lower limits of the $99 \%$ simulation envelope. Points above the upper envelope indicate clumped, points between the envelopes indicate random, and points below the lower envelope indicate regular
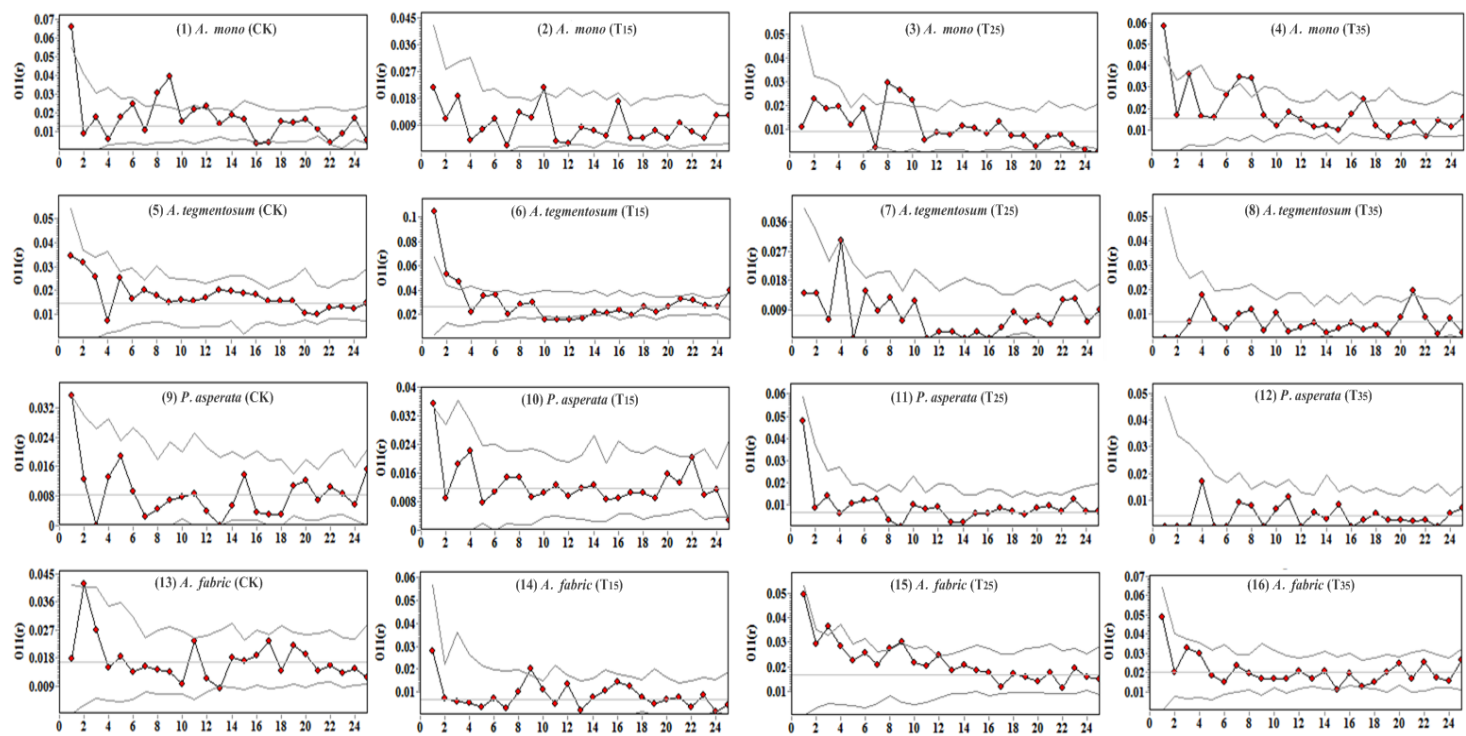

Figure 5. Univariate O-ring statistics of four dominant tree species under different thinning intensity

\section{Interspecies spatial associations of dominant tree species under different thinning intensities}

A. mono showed a slight positive correlation to A. tegmentosum at some scales in the $\mathrm{CK}$ plot, while the relationship between A. mono and A. tegmentosum was independent at almost all scales in 3 thinning plots (Fig. 6(1-4)). A. mono was dominated by inhibition to $P$. asperata and A. fabric at scales $\geq 12 \mathrm{~m}$ in the CK plot. However, in 3 thinning plots, A. mono was spatially independent of $P$. asperata and A. fabric at almost all scales and showed a slight positive correlation at some scales (Fig. 6(5-12)). A. tegmentosum and P. asperata were not correlated at all scales in all plots (Fig. 6(13- 
16)). The relationship of A. tegmentosum and A. fabric showed 3 different patterns (Fig. 6(17-20), (1) In the CK plot, A. tegmentosum was spatially independent of $A$. fabric at all scales. (2) In the $\mathrm{T}_{15}$ plot, A. tegmentosum was significantly positive correlation to $A$. fabric at scales was $2 \mathrm{~m}$. (3) Yet, in the $\mathrm{T}_{25}$ and $\mathrm{T}_{35}$ plots, $A$. tegmentosum was spatially independent of A. fabric at scales $\leq 12 \mathrm{~m}$, yet slight inhibition at scales greater than $12 \mathrm{~m}$. $P$. asperata was dominated by inhibition to $A$. fabric, such as at $3 \mathrm{~m}, 4-5 \mathrm{~m}, 12 \mathrm{~m}, 17 \mathrm{~m}$ and 21-23 $\mathrm{m}$ scales in the CK plot, while, in 3 thinning plots, it showed a slight positive correlation at $\geq 4 \mathrm{~m}$ scales.

The spatial associations between dominant tree species showed that the spatial associations of dominant tree species were mainly independent of different thinning intensities. In the CK plot, $A$. mono showed slight inhibition to A. tegmentosum, while it showed a slight positive correlation to $P$. asperata and A. fabric at different scales. Particularly, $P$. asperata showed strong negative correlation at many scales in response to A. fabric in the CK plot.
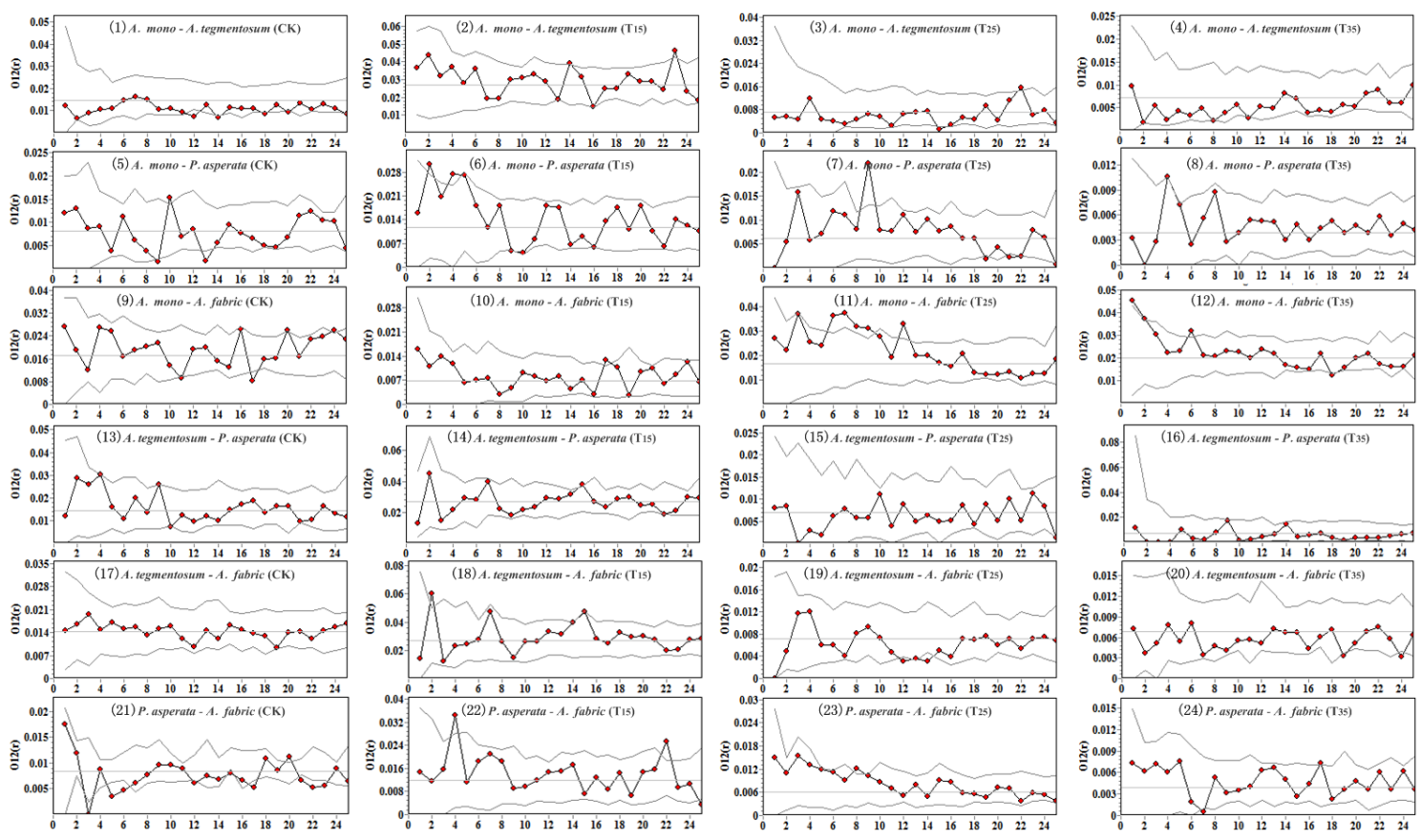

Figure 6. O12(r) values of spatial associations between different tree spices under different thinning intensity. Solid lines indicate ring statistics O12(r); Dotted lines indicate the upper and lower limits of the $99 \%$ simulation envelope of the CSR. Points above the upper envelope indicate positive associations, points between the envelopes indicate spatial independence, and points below the lower envelope indicate negative associations

\section{Spatial patterns of carbon reserves of dominant tree species under different thinning intensities}

It can be seen from Table 3 that the accumulative carbon storages in different thinning plots were different at the same scales. There was no difference in the cumulative carbon storages of dominant tree species between the CK plot and 3 thinning plots at $0-10 \mathrm{~m}$ scales. When the scales at $15 \mathrm{~m}, 20 \mathrm{~m}, 25 \mathrm{~m}, 30 \mathrm{~m}$, the cumulative carbon storage in the $\mathrm{T}_{15}$ plot was significantly different from those in the $\mathrm{CK}, \mathrm{T}_{25}$ and $\mathrm{T}_{35}$ plots. Compared with the $\mathrm{CK}$ plot, the cumulative carbon storages in 
the $\mathrm{T}_{15}$ plot were reduced by $38.67 \%, 44.04 \%, 41.86 \%$ and $41.38 \%$ at the $15 \mathrm{~m}, 20 \mathrm{~m}$, $25 \mathrm{~m}$ and $30 \mathrm{~m}$ scales, respectively. The carbon storage at $5 \mathrm{~m}, 10 \mathrm{~m}, 15 \mathrm{~m}$ and $20 \mathrm{~m}$ scales of the $\mathrm{T}_{25}$ plot was slightly lower than that of the CK plot, while the carbon storage at $25 \mathrm{~m}$ and $30 \mathrm{~m}$ scales was slightly higher than that of the CK plot, but there was no significant difference at all scales. However, in the $T_{35}$ plot, the cumulative carbon reserves at all scales were greater than those in the CK plot, but no significant difference.

Table 3. Cumulative carbon storage of dominant tree species at different scales

\begin{tabular}{c|c|c|c|c|c|c}
\hline \multirow{2}{*}{$\begin{array}{c}\text { Thinning } \\
\text { treatment }\end{array}$} & \multicolumn{5}{|c}{ Cumulative carbon storage at different scales (t) } \\
\cline { 2 - 7 } & $\mathbf{5 ~} \mathbf{~}$ & $\mathbf{1 0} \mathbf{~ m}$ & $\mathbf{1 5} \mathbf{~ m}$ & $\mathbf{2 0} \mathbf{~ m}$ & $\mathbf{2 5} \mathbf{~ m}$ & $\mathbf{3 0} \mathbf{~ m}$ \\
\hline $\mathrm{CK}$ & $0.05 \mathrm{a}$ & $0.23 \mathrm{a}$ & $0.75 \mathrm{a}$ & $1.09 \mathrm{a}$ & $1.72 \mathrm{a}$ & $2.61 \mathrm{a}$ \\
$\mathrm{T}_{15}$ & $0.03 \mathrm{a}$ & $0.23 \mathrm{a}$ & $0.46 \mathrm{~b}$ & $0.61 \mathrm{~b}$ & $1.00 \mathrm{~b}$ & $1.53 \mathrm{~b}$ \\
$\mathrm{~T}_{25}$ & $0.03 \mathrm{a}$ & $0.19 \mathrm{a}$ & $0.68 \mathrm{a}$ & $0.97 \mathrm{a}$ & $1.75 \mathrm{a}$ & $2.71 \mathrm{a}$ \\
$\mathrm{T}_{35}$ & $0.05 \mathrm{a}$ & $0.26 \mathrm{a}$ & $0.76 \mathrm{a}$ & $1.12 \mathrm{a}$ & $1.88 \mathrm{a}$ & $2.76 \mathrm{a}$ \\
\hline
\end{tabular}

\section{Discussion}

The study site was a natural secondary forest with complicated stand structure in Xiaoxing'an Mountains (Table 1, Figs. 2 and 3). Normally, the DBH class distribution of natural secondary forest is normal distribution. That means most of the individuals are middle DBH, while individuals with large and small DBH are fewer (Wang, et al., 2017; Duan et al., 2019). Thinning changed the DBH class distribution of trees (Hu et al., 2011). In this experiment, the DBH of dominant tree species in the CK plot was normal distribution, while thinning caused the distribution curve to deviate from the normal. The average DBH of dominant tree species in the $\mathrm{T}_{35}$ plot was significantly higher than other thinning plots. We could infer that thinning also release the pressure of competition among reserved trees and promote the growth of natural secondary forests. This was the same as Hu's conclusion (Hu et al., 2011).

Four experimental plots have different gaps, different soil nutrient conditions and different light intensity, which caused the difference of spatial and carbon patterns. Meanwhile, these factors will cause uneven distribution of forest resources ( $\mathrm{He}$ and Duncan, 2000; Boyden et al., 2005; Druckenbrod et al., 2005). With the thinning intensity increasing, the aggregation phenomena of $A$. mono increased. The reasons were that it had weak positive biological characteristics and responses to the gaps. Evenly distributed gaps and upper canopy gaps provided space and opportunity for the growth of $A$. mono (Huang et al., 2004). The aggregation phenomena of A. tegmentosum could also be explained by the above content. A. fabric were aggregated around their parent trees under smaller thinning intensities (Figs. 5(10) and 5(13-15)). Limited seed dispersal ability provided seed sources for seedling and sapling recruitment, while shade-tolerant characteristics ensured that seedlings and saplings could grow well under the canopy of parent trees (Hou et al., 2004). P. asperata and A. fabric mainly showed significant clustering at small scales. As the scale increased, the aggregation of trees began to decrease and showed random distribution gradually, which was similar to the results reported in the literature (Liu et al., 2005). The scale variability of the forest spatial patterns is restricted by many factors. On one hand, at small scales, different spatial patterns may be caused by varying degrees of intra- and interspecies competitions, restriction of seed dispersal, etc. On the other hand, at large scales, different spatial patterns may be determined by the 
heterogeneity or plaque-type of species distribution and the nonbiological environments (topography, soil moisture, soil pH, soil nutrients, etc.) (He et al., 1997; Harms et al., 2000; Zhang et al., 2008; Wang et al., 2008).

Spatial correlation is used to describe the static relationship of dominant tree species in spatial distribution. The dominant tree species showed mainly independent at different scales in four experimental plots, this was the important reason for the stable distribution of dominant tree species for a long time (Shen et al., 2013). A. mono and $A$. tegmentosum have similar ecological habits. In the CK plot, $A$. mono showed spatial independence at small scales, and were negatively associated at larger scales to $A$. tegmentosum. $P$. asperata also showed strong negative correlation at many scales in response to A. fabric in the CK plot, Because they had similar ecological habits. However, thinning changed the distributions of dominant tree species and the correlation of dominant tree species tended to positive correlations or independent, which were more conducive to the growth of the forest. A. tegmentosum and A. fabric were positively correlated at some scales and negatively correlated at some scales, because this study neglected the law of spatial correlation between two dominant tree species of different DBH classes.

Particularly, the cumulative carbon storages depend on the species of trees, the number of trees and the carbon storage of individual tree at this scale. In our study, the accumulative carbon storages at different spatial scales were different under different thinning intensities. When the scale $\leq 10 \mathrm{~m}$, there was no significant difference in carbon storage between the $\mathrm{CK}$ plot and 3 thinning plots. At $>10 \mathrm{~m}$ scales, the accumulative carbon storages in the $\mathrm{T}_{15}$ plot was significantly smaller than those in other plots. It indicates that $15 \%$ thinning intensity was not conducive to the accumulation of carbon reserves. Ding (2016) and Han (2015) have shown that thinning could removing part of trees that would reduce carbon reserves. However, Duan (2019) suggested that carbon storage would recover after a period of time. Shen (2013) believed that thinning released competitive pressure of trees, which was conducive to the increase of carbon storage. In this experiment, the cumulative carbon storages in the $\mathrm{T}_{25}$ and $\mathrm{T}_{35}$ plots were not significantly different from those in the CK plot at all scales, particularly, the cumulative carbon storages in the $T_{35}$ plot was larger than that in the $\mathrm{CK}$ plot at all scales, indicating that reasonable thinning would not reduce carbon storages. It was consistent with the research results of Duan (2019), Shen (2013), etc.

\section{Conclusion}

Our results clearly showed that the competition pressure of natural mixed broadleafconifer secondary forest in Xiaoxing'an Mountains was released after 8 years of thinning, and the stand structure was optimized, so that the reserved trees could grow better. Through the analysis of spatial point patterns, the spatial distribution feature points were found, which had guiding significance for forest management. For example, thinning should be reduced in areas with few trees, and should be appropriately increased in tree gathering areas to release competition pressure among trees. Evenly distributed forests can help plants make better use of light and make plants grow better. The cumulative carbon storages of the forest in the $\mathrm{T}_{35}$ plot were almost higher than those in the CK plot at all scales. And the results showed that the cutting intensity of $35 \%$ could promote the optimization of the stand structure and it was beneficial to the carbon sink of natural mixed broadleaf-conifer secondary forest in Xiaoxing'an Mountains. 
The stand structure characteristics of natural secondary forests are very complex, and the sample plots set in Xiaoxing'an Mountains could only represent the growth status of the stand in this range, which had some limitations, other representative stands should be added to make the data more comprehensive. Forest structure is a dynamic process of long-term change, and it should be observed and analyzed for a longer period of time by extending restoration period. On the basis of this study, the effects of different tending and thinning intensities on the spatial and carbon distribution patterns of shrubs and herbs can be explored to form different hierarchical relationships and network structures. Finally, combine the research results of various aspects to better determine the ideal thinning intensity.

Acknowledgements. This study was financially supported by the Research and development plan of Applied Technology in Heilongjiang Province of China (GA19C006). And the data source was supported by field investigation in 2019 .

\section{REFERENCES}

[1] Aakala, T., Fraver, S., Palik, B. J., D'Amato, A. W. (2012): Spatially random mortality in old-growth red pine forests of northern Minnesota. - Can. J. For. Res 42: 899-907.

[2] Baddeley, A., Turner, R. (2005): Spatstat: an R package for analyzing spatial point patterns. - J. Stat. Software 12: 1-42.

[3] Boyden, S., Binkley, D., Shepperd, W. (2005): Spatial and temporal patterns in structure, regeneration, and mortality of an old-growth ponderosa pine forest in the Colorado Front Range. - For. Ecol. Manage 219: 43-55.

[4] Diggle, P. J. (2003): Statistical Analysis of Spatial Point Patterns. - Arnold, London.

[5] Ding, B., Ding, G. J., Li, X. Z., Yang, Y. Z. (2016): Effects of short-term thinning on the carbon storage in Cunninghamia lanceolata plantation ecosystem. - Journal of Central South University of Forestry \& Technology 36(08): 66-71.

[6] Druckenbrod, D. L., Shugart, H. H., Davies, I. (2005): Spatial pattern and process in forest stands within the Virginia piedmont. - J. Veg. Sci 16(1): 37-48.

[7] Du, Z., Kang, X. G., Bao, Y. J., Yang, X. X. (2012): Spatial distribution patterns and associations of tree species during different succession stages in spruce-fir forests of Changbai Mountains, northeastern China. - Journal of Beijing Forestry University 34(02): 14-19.

[8] Du, Z., Kang, X. G., Meng, J., H., Kong, L., Guo, W. W., Yue, G. (2013): Spatial distribution patterns and associations of dominant tree species in poplar birch secondary forest stand in Changbai Mountains. - Journal of Northeast Forestry University 41(04): $36-42$.

[9] Duan, M. C., Wang, G. L., Shi, J. Y., Zhou, H. X. (2019): Effects of thinning on structure and spatial pattern of dominant populations in Pinus tabuliformis plantations. - Chinese Journal of Ecology 38(01): 1-10.

[10] Fajardo, A., Goodburn, J. M., Graham, J. (2006): Spatial patterns of regeneration in managed uneven-aged ponderosa pine/Douglas-fir forests of Western Montana, USA. For. Ecol. Manage 223(1-3): 255-266.

[11] Felinks, B., Wiegand, T. (2008): Exploring spatiotemporal patterns in early stages of primary succession on former lignite mining sites. - J. Veg. Sci 19: 267-276.

[12] Getzin, S., Dean, C., He, F., Trofymow, J. A., Wiegand, K., Wiegand, T. (2006): Spatial patterns and competition of tree species in a Douglas-fir chronosequence on Vancouver Island. - Ecography 29: 671-682. 
[13] Gray, L., He, F. (2009): Spatial point-pattern analysis for detecting density-dependent competition in a boreal chrono sequence of Alberta. - For. Ecol. Manag. 259: 98-106.

[14] Han, F. L., Tian, X. L., Dang, S. L., Cao, T. J. (2015): Impact of thinning on carbon storage for Pinus tabuliformis stands in Shaanxi Qiaoshan. - Journal of Northwest Forestry University 30(04): 184-191.

[15] Hao, Z. Q., Zhang, J., Song, B., Ye, J., Li, B. H. (2007): Vertical structure and spatial associations of dominant tree species in an old-growth temperate forest. - For. Ecol. Manage 252: 1-11.

[16] Harms, K. E., Wright, S. J., Calderón, O., Hernóndez, A., Herre, E. (2000): Pervasive density-dependent recruitment enhances seedling diversity in a tropical forest. - Nature 404: 493-495.

[17] He, F., Duncan, R. P. (2000): Density-dependent effects on tree survival in an old growth Douglas fir forest. - J. Ecol 88: 676-688.

[18] He, F., Legendre, P. L., Frankie, J. V. (1997): Distribution patterns of tree species in a Malaysian tropical rain forest. - Journal of Vegetation Science 8: 105-114.

[19] Hou, J., Mi, X., Liu, C., Ma, K. (2004): Spatial patterns and associations in a QuercusBetula forest in northern China. - J. Veg. Sci 15(3): 407-414.

[20] Hu, Y. Y., Min, Z. Q., Gao, Y., Feng, Q. X. (2011): Effects of selective cutting on stand growth and structure for natural mixed spruce (Picea koraiensis) fir (Abies nephrolepis) forests. - Scientia Silvae Sinicae 47(02): 15-24.

[21] Hu, H. Q., Luo, B. Z., Wei, S. J., Sun, L., Luo, S. S., Ma, H. B. (2015): Biomass carbon density and carbon sequestration capacity in seven typical forest types of the Xiaoxing'an Mountains, China. - Chinese Journal of Plant Ecology 39(02): 140-158.

[22] Huang, X. F., Kang, X. G. (2004): A review on the study of regeneration of natural spruce-fir mixed stand of coniferous and broad-leaved trees in China. - World Forestry Research 5: 34-38.

[23] Illian, J., Penttinen, A., Stoyan, H., Stoyan, D. (2008): Statistical Analysis and Modelling of Spatial Point Patterns. - John Wiley \& Sons, Chichester, UK.

[24] Law, R., Illian, J., Burslem, D. F. R. P., Gratzer, G., Gunatilleke, C. V. S., Gunatilleke, I. A. U. N. (2009): Ecological information from spatial patterns of plants: insights from point process theory. - Journal of Ecology 97: 616-628.

[25] Li, R., Zhang, W. H., He, J. F., Zhou, J. Y. (2011): Effect of thinning on natural regeneration and growth of Quercus wutaishanica saplings. - Journal of Northwest A \& F University (Natural Science Edition) 39(01): 52-60 + 68 .

[26] Liu, Z. G., Li, Z. Q. (2005): Perspectives on small-scale spatial structure of plant species in plant communities. - Acta Phytoecologica Sinica 29(6): 1020-1028.

[27] Moeur, M. (1993): Characterizing spatial patterns of trees using stem-mapped data. Forest Science 4(39): 756-775.

[28] Petritan, I. C., Marzano, R., Petritan, A. M., Lingua, E. (2014): Overstory succession in a mixed Quercus petraea-Fagus sylvatica old growth forest revealed through the spatial pattern of competition and mortality. - Forest Ecology \& Management 326: 9-17.

[29] Rozas, V. (2006): Structural heterogeneity and tree spatial patterns in an old-growth deciduous lowland forest in Cantabria, northern Spain. - Plant Ecology (185): 57-72.

[30] Sanatan, D. G., Bradley, D. P. (2018): Spatial patterns and competition in trees in early successional reclaimed and natural boreal forests. - Acta Oecologica 92: 138-147.

[31] Shen, L., Yang, H., Kang, X. G., Yue, G. (2013): Effects of selective cutting intensity on spatial distribution pattern of natural spruce-fir forests. - Journal of Central South University of Forestry \& Technology 33(01): 68-74.

[32] Stoyan, D., Penttinen, A. (2000): Recent applications of point process methods in forestry statistics. - Statistical Science 15(1).

[33] Stoyan, D., Stoyan, H. (1994): Fractals, Random Shapes and Point Fields. - Wiley, Chichester. 
[34] Svoboda, M., Fraver, S., Janda, P., Bače, R., Zenáhlíková, J. (2010): Natural development and regeneration of a Central European montane spruce forest. - Forest Ecology \& Management 260: 707-714.

[35] Wang, C. K. (2005): Biomass allometric equations for 10 co-occurring tree species in Chinese temperate forests. - Forest Ecology and Management 222(1).

[36] Wang, X. G., Hao, Z. Q., Ye, J., Zhang, J., Li, B. H., Yao, X. L. (2008): Relationships between species abundance and spatial distribution pattern of broad-leaved Korean pine (Pinus koraiensis) mixed forest in Changbai Mountains of China. - Chinese Journal of Ecology 27(2): 145-150.

[37] Wang, Y., Bi, R. C., Xu, Q. (2017): Community characteristics and spatial distribution of mixed conifer and broad-leaved forest in South Taiyue Mountain, Shanxi Province of China. - Guihaia 37(07): 901-911.

[38] Wiegand, T., Moloney, K. A. (2004): Rings, circles, and null-models for point pattern analysis in ecology. - Oikos 104: 209-229.

[39] Wiegand, T., Moloney, K. A. (2014): A Handbook of Spatial Point Pattern Analysis in Ecology. - Chapman and Hall/CRC Press, Boca Raton, FL.

[40] Wu, J. Q., Wang, Y. X., Yang, Y., Zhu, T. T., Zhu, X. D. (2015): Effects of crop tree release on stand growth and stand structure of Cunninghamia lanceolata plantation. Chinese Journal of Applied Ecology 26(02): 340-348.

[41] Yang, H., Li, D. (1985): Distribution patterns of dominant tree species on northern slope of Changbai Mountain. - Research Forest. Ecosyst. 5: 1-14.

[42] Yao, H. F., Wang, C., Lu, J. (2020): Survey of research on spatial distribution pattern of plant population. - Agricultural Development \& Equipment (10): 113-115.

[43] Zhang, C. Y., Zhao, X. H., Xia, F. C. (2008): Spatial distribution of tree species and environmental interpretations of secondary forest in Changbai Mountains. - Scientia Silvae Sinicae 44(8): 1-8.

[44] Zhao, Z. H., Hui, G. Y., Hu, Y. B., Zhou, H. M., Zhang, L. J. (2011): Spatial distribution patterns and associations of dominate population in two types of broadleaved Korean pine mixed forest. - Forest Research 24(05): 554-562. 